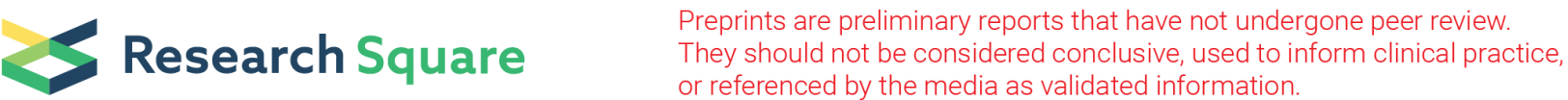

\section{Effect of Timely Lactate Measurement on In- hospital Mortality among Adults with Hypotension and Hyperlactatemia: An Observational Study on Two Cohorts}

\section{Hui Chen}

First Affiliated Hospital of Soochow University

\section{Xiebing Bao}

First Affiliated Hospital of Soochow University

\section{Ying Xu}

First Affiliated Hospital of Soochow University

\section{Yanxia Guo}

First Affiliated Hospital of Soochow University

\section{Mingqin Zhou}

Shantou University Medical College Cancer Hospital

\section{Chenyan Zhao}

First Affiliated Hospital of Soochow University

\section{Yao Wei}

First Affiliated Hospital of Soochow University

Jun Jin ( $\square$ jinjun0514@163.com )

First Affiliated Hospital of Soochow University https://orcid.org/0000-0002-8778-5247

\section{Research}

Keywords: Hypotension, Hyperlactatemia, Lactate measurement, In-hospital mortality

Posted Date: August 25th, 2020

DOl: https://doi.org/10.21203/rs.3.rs-60524/v1

License: (c) (i) This work is licensed under a Creative Commons Attribution 4.0 International License. Read Full License 


\section{Abstract}

Background: Whether patients presented with hypotension and hyperlactatemia can benefit from timely lactate measurement and further lactate-guide resuscitation were not fully understood.

Methods: This was a retrospective observational study based on the data from the Medical Information Mart for Intensive Care (MIMIC)-III Database and the eICU Collaborative Research Database (eICU). Patients with hypotension (defined as a minimal systolic blood pressure $\leq 90 \mathrm{~mm} \mathrm{Hg}$ or minimal mean arterial pressure $\leq 65 \mathrm{~mm} \mathrm{Hg}$ or requiring any vasopressors support during the first $24 \mathrm{~h}$ after ICU admission) and hyperlactatemia (defined as an initial lactate level $>2.0 \mathrm{mmol} / \mathrm{L}$ after ICU admission) were eligible.The primary exposure was the timely lactate measurement, which was defined as an initial lactate level measured within $1 \mathrm{~h}$ after ICU admission. The primary outcome was in-hospital mortality. The statistical approaches included multivariate regression, propensity score matching (PSM) and an inverse probability of treatment weighing (IPTW) and causal mediation analysis (CMA) were utilized to elucidate the relationship between timely lactate measurement and in-hospital mortality.

Results: A total of 9978 patients were identified, of which 4257 in MIMIC-III and 5721 in elCU. Timely lactate measurement was associated with lower risk-adjusted in-hospital mortality both in MIMIC (OR $0.70(95 \% \mathrm{Cl} 0.58-0.85 ; p<0.001))$ and elCU (OR $0.75(95 \% \mathrm{Cl} 0.64-0.88 ; p<0.001))$. Time to initial intravenous fluid (IVF) in MIMIC mediated 6.7\% $(95 \% \mathrm{Cl} 1.4 \%-38 \%$; $p<0.001)$ of the beneficial effect of timely lactate measurement ( $<<0.001$ for average causal mediation effect (ACME)) in terms of in-hospital mortality. Finally, delayed initial lactate measurements are also associated an increased in-hospital mortality in MIMIC and eICU.

Conclusions: Timely lactate measurement is associated with a lower risk-adjusted in-hospital mortality among patients with hypotension and hyperlactatemia, which was proportional mediated through shortening the time to IVF. Delay in initial lactate measurement showed a positive association with inhospital mortality.

\section{Introduction}

Since lactate measurement was first described by Scherer in 1843 , blood lactate level measurement was performed widely in critically ill patients, especially in patients with shock [1,2]. On the one hand, elevated lactate levels in shock is a predictor of poor clinical outcome as a biomarker of tissue hypoperfusion [3], On the other hand, lactate level is an effective parameter for guiding resuscitation during the early phase of shock [4-7]. Furthermore, clinical therapy according to the elevated lactate level is believed to be associated with increased risk of death when delayed [8]. Thus, shorter the time to initial lactate level measurement is of vital importance to the management of shock. However, considerable controversies still exist in regarding how rapidly measurement of lactate level should be performed in critically ill patients with shock. 
Few studies have focused on assessing optimal time to initial lactate measurement after intensive care unit (ICU) admission and its effect on outcome in septic patients. Pruinelli et al. [9]concluded that for patients with severe sepsis or septic shock, a delay of 20 minute in initial lactate level measurement significantly increased the risk of in-hospital mortality, and the lactate recommendation had minimum statistically significant time compared with other 3-hour bundle recommendations. The latest sepsis campaign guideline [10]also emphasized that the initial lactate level should be performed within $1 \mathrm{~h}$ despite of no strong evidence of benefit. Notably, even though many groups have demonstrated in circulatory shock that hyperlactemia was associated with elevated morbidity and mortality [11-15], but whether all patients presented with circulatory shock or unstable hemodynamics can benefit from timely lactate level measurement and further lactate-guide resuscitation were not fully understood.

The present study was undertaken to elucidate the relationship between timely lactate measurement (within $1 \mathrm{~h}$ after ICU admission) and outcomes and influences of timely lactate measurement on interventions in patients with hypotension and hyperlactatemia $(>2.0 \mathrm{mmol} / \mathrm{L})$. In addition, we attempted to characterize the association of delays in initial lactate measurement with mortality to further understand the effectiveness of timely lactate measurement.

\section{Methods}

\section{Study design}

We conducted a retrospective cohort study based on two databases from critically ill patients admitted to the ICU, the Medical Information Mart for Intensive Care (MIMIC)-III [16], and the elCU Collaborative Research Database (eICU) [17]. The data of MIMIC-III (v1.4) was associated with 53423 distinct hospital admissions for adult patients admitted to ICUs at the Beth Israel Deaconess Medical Center between 2001 and 2012. The elCU (v1.2) covers over 200000 patients who were admitted to one of 335 ICUs at 208 hospitals located in the United States (US) from 2014 to 2015. The access of two databases was obtained by the Certification Number of 27252652.

\section{Study population}

The patients in the MIMIC-III and eICU databases who were aged 18 years or older were eligible if they had (1) hypotension (defined as a minimal systolic blood pressure $\leq 90 \mathrm{~mm} \mathrm{Hg}$ or minimal mean arterial pressure $\leq 65 \mathrm{~mm} \mathrm{Hg}$ or requiring any vasopressors support during the first $24 \mathrm{~h}$ after ICU admission) and (2) hyperlactatemia (defined as an initial lactate level $>2.0 \mathrm{mmol} / \mathrm{L}$ after ICU admission). Based on the setting of previous researches, we excluded patients who spent less than $48 \mathrm{~h}$ in the ICU and patients without any measurement of lactate level within $24 \mathrm{~h}$ after ICU admission. Additionally, we only analyzed the first ICU stay for patients who were admitted to the ICU more than once. The primary exposure was the timely lactate measurement, which was defined as an initial lactate level measured within $1 \mathrm{~h}$ after ICU admission. The enrolled patients were further divided into two groups as follows: the initial lactate 
level was measured within $1 \mathrm{~h}$ after ICU admission (Lac-by1 group); the initial lactate level was measured more than $1 \mathrm{~h}$ after ICU admission (Lac-after1 group).

\section{Data extraction}

Time to initial lactate level measurements were calculated depend on the length of admission to ICU. Other variables of interest were also extracted from the MIMIC and eICU using structured query language (SQL) (Additional file 1: Additional Methods).

\section{Outcomes}

The primary outcome of our study was in-hospital mortality. Secondary outcomes including the time to initial vasopressor administration (hours); time to initial intravenous fluid (IVF) treatment (hours); volume (L) of IVF administered during their first $6 \mathrm{~h}, 24 \mathrm{~h}$ in the ICU.

\section{Statistical analysis}

Values were presented as mean (standard deviation) or median [interquartile range (IQR)] for continuous variables as appropriate, and frequency for categorical variables. Comparison between groups were made using $X^{2}$ test or Fisher's exact test for categorical variables and student's $t$ test, or Mann-Whitney $U$ test for continuous variables as appropriate.

Timely lactate measurement was used as a binary variable for the primary analysis. Multivariate regression was selected to characterize the relationship between timely lactate measurement and inhospital mortality. In the eICU, to responsible for potential changes of clinical practice in different centers, an analysis including center as a random factor in mixed-effect models was performed. To avoid bias induced by missing data, the analysis of the primary outcome was duplicated after multiple imputation. Propensity score matching (PSM) [18]and propensity score-based inverse probability of treatment weighing (IPTW) [19]were also used for adjusting the covariates to ensure the robustness of our findings. To explore whether the effect of timely lactate measurement on the primary outcome is mediated by the interventions, we used causal mediation analysis (CMA) [20]to searching for key interventions including the time to IVF and time to initial vasopressor administration that could be linked to positive outcomes after timely lactate measurement (Additional file 1: Additional Methods).

Time to initial lactate measurement was then used as a continuous variable for the other analysis. Restricted Cubic Spline were used to detect the possible nonlinear relationship between the risk of inhospital death and time to initial lactate measurement. Moreover, we analyzed the time to initial lactate measurement partitioned into 5 quantiles to clarify the relationship further in two cohorts. 
All statistical analyses were performed using the RStudio (version 1.2.5019), and $p<0.05$ was considered statistically significant.

\section{Results}

\section{Baseline characteristics}

After reviewing 53423 MIMIC-III adult admissions, a total of 4257 unique patients admitted from 2001 till 2012 both fulfilled the definition of hypotension and hyperlactatemia. In eICU, we had enrolled 5721 unique patients from 200859 admissions admitted from 2014 till 2015 in our study. The flow diagrams of study patients are presented in Figure S1 and S2 (Additional file 1), respectively.

The baseline characteristics of two cohorts are summarized in Table 1 and Table S1 (Additional file 1); characteristics of ICUs involved are presented in Table S2 (Additional file 1). In MIMIC-III, the minimum mean arterial pressure (MAP) was $54 \mathrm{mmHg}(\mathrm{IQR}, 48-60 \mathrm{mmHg}$ ), and the initial lactate level was 3.2 $\mathrm{mmol} / \mathrm{L}$ (IQR, 2.5-4.4 mmol/L); in eICU, the minimum MAP was $64.3 \mathrm{mmHg}$ (IQR, 55.7-71.3 $\mathrm{mmHg}$ ), and the initial lactate level was $3.4 \mathrm{mmol} / \mathrm{L}(\mathrm{IQR}, 2.6-5.2 \mathrm{mmol} / \mathrm{L})$. Time to initial lactate level measurement was $2.1 \mathrm{~h}$ (IQR, 0.9-5.0 h) in MIMIC and 2.1 h (IQR, 0.9-5.1 h) in elCU. Overall in-hospital mortality was $22.0 \%$ in MIMIC-III and $29.0 \%$ in elCU. 
Table 1

Baseline characteristics of the included patients in two cohorts

\begin{tabular}{|c|c|c|}
\hline \multirow[t]{2}{*}{ Characteristic } & MIMIC-III & elCU \\
\hline & $(n=4257)$ & $(n=5721)$ \\
\hline Age (years) & $68(55-78)$ & $65(54-75)$ \\
\hline Male & $2411 / 4257(56.6)$ & $2551 / 5721(44.6)$ \\
\hline Weight (kg) & $79(66.4-93)$ & $80.1(66.6-98)$ \\
\hline Service unit (MICU \%) & $1257 / 4257(29.5)$ & $3938 / 5721(68.8)$ \\
\hline \multicolumn{3}{|l|}{ Admission period, n (\%) } \\
\hline Before 2008 (2014) & 2418/4257 (56.8) & $2563 / 5721(44.8)$ \\
\hline 2008-2012/ (2015) & 1839/4257 (43.2) & $3158 / 5721$ (55.2) \\
\hline \multicolumn{3}{|l|}{ Severity of illness } \\
\hline SOFA score & $7(4-9)$ & $8(5-11)$ \\
\hline SAPS II score & $44(35-54)$ & - \\
\hline OASIS score & $37(32-43)$ & $44(35-52)$ \\
\hline APACHE IV score & - & $83(65-106)$ \\
\hline Elixhauser comorbidity score & $5(0-11)$ & - \\
\hline \multicolumn{3}{|l|}{ Interventions, n (\%) } \\
\hline Mechanical ventilation ( $1^{\text {st }} 24 \mathrm{~h}$ ) & $3565 / 4257(83.7)$ & $3104 / 5721(54.3)$ \\
\hline Vasopressor ( $\left.1^{\text {st }} 24 \mathrm{~h}\right)$ & $2855 / 4257(67.1)$ & $2795 / 5721(48.9)$ \\
\hline \multicolumn{3}{|l|}{ Comorbidities, n (\%) } \\
\hline $\mathrm{CHF}$ & $620 / 4257(14.5)$ & $677 / 5721(11.8)$ \\
\hline Chronic renal disease & $523 / 4257(12.3)$ & 715/5721 (12.5) \\
\hline Liver disease & $342 / 4257(8)$ & $332 / 5721(5.8)$ \\
\hline COPD & $668 / 4257(15.7)$ & $816 / 5721(14.3)$ \\
\hline Stroke & 125/4257 (3.0) & $443 / 5721(7.7)$ \\
\hline Malignancy & $187 / 4257(4.4)$ & $859 / 5721(15)$ \\
\hline \multicolumn{3}{|l|}{ Vital signs } \\
\hline Minimum SBP (mmHg) & $82(73-90)$ & $74(64-83)$ \\
\hline Maximum Heart rate (bpm) & $109(95-124)$ & $129(115-146)$ \\
\hline
\end{tabular}




\begin{tabular}{|c|c|c|}
\hline Maximum Temperature $\left({ }^{\circ} \mathrm{C}\right)$ & $37.7(37.2-38.2)$ & $38.1(37.5-38.8)$ \\
\hline Maximum Respiratory rate (bpm) & $28(24-32)$ & $35(30-42)$ \\
\hline Initial lactate level (mmol/L) & $3.2(2.5-4.4)$ & $3.4(2.6-5.2)$ \\
\hline Time to initial lactate level measurement (h) & $2.1(0.9-5.0)$ & $2.1(0.9-5.1)$ \\
\hline \multicolumn{3}{|l|}{ Time of ICU admission, n (\%) } \\
\hline 0:00 - 8:00 & $1901 / 4257(44.7)$ & $1234 / 5721(21.6)$ \\
\hline 8:00 -16:00 & $1490 / 4257(35)$ & $2228 / 5721(38.9)$ \\
\hline $16: 00-24: 00$ & $866 / 4257(20.3)$ & $2259 / 5721(39.5)$ \\
\hline \multicolumn{3}{|c|}{$\begin{array}{l}\text { MICU: Medical Intensive Care Unit; SOFA: Sequential Organ Failure Assessment; SAPS II: Simplified } \\
\text { Acute Physiology Score II; OASIS: Overall Anxiety Severity and Impairment Scale; APACHE IV: Acute } \\
\text { Physiology and Chronic Health Evaluation IV; CHF: Congestive Heart Failure; COPD: Chronic } \\
\text { Obstructive Pulmonary Disease; MAP: Mean Arterial Pressure; ICU: Intensive Care Unit. }\end{array}$} \\
\hline
\end{tabular}

\section{Time to initial lactate level measurements}

Distributions of time to initial lactate level measurements in two cohorts are seen in Figure S3 (Additional file 1). In MIMIC, 1189 (25.1\%) patients drawn the initial lactate level within $1 \mathrm{~h}$ after ICU admission (Lacby1), with a median value of $3.4 \mathrm{mmol} / \mathrm{L}$ (IQR, 2.6-5 mmol/L). 1650 (28.8\%) patients of the elCU cohort had initial lactate level measurements completed within $1 \mathrm{~h}$ after ICU admission (Lac-by 1 ), with a median value of $3.6 \mathrm{mmol} / \mathrm{L}(\mathrm{IQR}, 2.7-5.6 \mathrm{mmol} / \mathrm{L})$. The characteristics of Lac-by 1 and Lac-after 1 groups are shown in Table S3 and S4 (Additional file 1).

\section{Primary outcome}

Results of the univariate analyses in two cohorts are presented in Table S5 (Additional file 1), the full multivariate logistic regression analyses are showed in Figure 1 and Table S6 (Additional file 1), the adjusted odds ratio (OR) was $0.70(95 \% \mathrm{Cl} 0.58-0.85 ; \mathrm{p}<0.001)$ in MIMIC and $0.75(95 \% \mathrm{Cl} 0.64-0.88$; $p<0.001)$ in elCU. Moreover, this beneficial effect was not only confirmed after multiple imputation (Additional file 1: Table S7 and S8), but also in the models when using PSM and IPTW (Additional file 1: Table S3 and S4, Figure S4 and S5) for adjusting the covariates in two cohorts. On average, the completion of initial lactate measurement within $1 \mathrm{~h}$ after ICU admission was associated with lower riskadjusted in-hospital mortality for patients with hypotension and hyperlactatemia both in MIMIC and elCU.

Subgroups analysis were completed in both cohorts (Additional file 1: Figure S6). Briefly, timely lactate measurement was associated with improved outcome despite of the different initial lactate level (2-4; $\geq 4)$, the Sequential Organ Failure Assessment (SOFA) score $(<10 ; \geq 10)$ and minimal MAP $(<65 ; \geq 65)$, while no statistically significant interaction were detected. 


\section{Secondary outcomes with propensity score matched cohorts}

Therapeutic interventions including vasopressor and IVF that might mediate the beneficial effect of timely lactate measurement on in-hospital mortality were investigated. First, patients in the Lac-by1 group had a shorter time to initial any vasopressor administration in MIMIC and eICU, and a shorter time to initial norepinephrine in MIMIC when administered. Second, compared with Lac-after1 group, Lac-by1 group had a significant shorter time to IVF and received more IVF within $6 \mathrm{~h}$ in two cohorts (Table 2).

Table 2

Secondary outcomes analysis with propensity score matched cohorts in MIMIC-III and eICU

\begin{tabular}{|c|c|c|c|c|c|c|}
\hline \multirow[t]{2}{*}{ Secondary outcomes } & \multicolumn{3}{|l|}{ MIMIC-III } & \multicolumn{3}{|l|}{ eICU } \\
\hline & Lac-by1 & Lac-after1 & $\begin{array}{l}\mathrm{P} \\
\text { value }\end{array}$ & Lac-by1 & $\begin{array}{l}\text { Lac- } \\
\text { after1 }\end{array}$ & $\begin{array}{l}\mathrm{P} \\
\text { value }\end{array}$ \\
\hline $\begin{array}{l}\text { Time to initial any } \\
\text { vasopressor }(h)\end{array}$ & $\begin{array}{l}2.7(1.4- \\
5.8)\end{array}$ & $\begin{array}{l}3.9(1.9- \\
8.3)\end{array}$ & $<0.001$ & $\begin{array}{l}2.6(0.9- \\
10.2)\end{array}$ & $\begin{array}{l}3.5(1.0- \\
13.8)\end{array}$ & 0.011 \\
\hline $\begin{array}{l}\text { Time to initial } \\
\text { norepinephrine (h) }\end{array}$ & $\begin{array}{l}3.7(1.7- \\
14.5)\end{array}$ & $\begin{array}{l}6.1(2.3- \\
20.0)\end{array}$ & 0.001 & $\begin{array}{l}4.0(1.2- \\
12.0)\end{array}$ & $\begin{array}{l}4.4(1.1- \\
12.3)\end{array}$ & 0.602 \\
\hline Time to IVF (h) & $\begin{array}{l}3.3(1.9- \\
6.2)\end{array}$ & $\begin{array}{l}4.4(2.4- \\
7.2)\end{array}$ & $<0.001$ & $\begin{array}{l}1.8(0.8- \\
5.8)\end{array}$ & $\begin{array}{l}3.0(0.8- \\
7.2)\end{array}$ & 0.004 \\
\hline IVF within 6 h (L) & $\begin{array}{l}1.6(1.0- \\
3.0)\end{array}$ & $\begin{array}{l}1.5(1.0- \\
2.0)\end{array}$ & 0.002 & $\begin{array}{l}1.3(0.5- \\
2.8)\end{array}$ & $\begin{array}{l}1.0(0.4- \\
2.2)\end{array}$ & 0.004 \\
\hline IVF within 24 h (L) & $\begin{array}{l}2.5(1.25- \\
4.25)\end{array}$ & $\begin{array}{l}2.5(1.25- \\
4.0)\end{array}$ & 0.245 & $\begin{array}{l}3.0(1.3- \\
5.6)\end{array}$ & $\begin{array}{l}2.9(1.2- \\
5.4)\end{array}$ & 0.607 \\
\hline
\end{tabular}

\section{Test of mediation}

We further confirmed whether the beneficial effect of timely lactate measurement on in-hospital mortality is mediated through therapeutic interventions. After causal mediation analysis, we found that the time to IVF in MIMIC mediated $6.7 \%(95 \% \mathrm{Cl} 1.4 \%-38 \% ; p<0.001)$ of the beneficial effect of timely lactate measurement ( $<0.001$ for average causal mediation effect (ACME)) (Figure 2). However, when using time to IVF in elCU or time to initial vasopressor administration in MIMIC and elCU as mediator, the mediation effect was insignificant (Additional file 1: Table S9). Thus, survival benefit of the timely lactate measurement was proportional mediated through shortening the time to IVF.

\section{Delayed initial lactate measurement and in-hospital mortality}


Figure 3 shows the increase in the adjusted odds of in-hospital mortality as a contribution of progressive percentiles of time to initial lactate measurement in MIMIC (Figure 3A) and eICU (Figure 3B). Specifically, the adjusted odds ratio (OR) of in-hospital mortality was 1.03 per hour delay $(95 \% \mathrm{Cl} 1.01-1.04 ; \mathrm{p}=0.002)$ in MIMIC and 1.04 per hour delay $(95 \% \mathrm{Cl} 1.02-1.05 ; p<0.001)$ in eICU.

\section{Discussion}

Our investigation yielded three major findings: (1) Timely lactate measurement (within $1 \mathrm{~h}$ after ICU admission) was associated with lower risk-adjusted in-hospital mortality in patients with hypotension and hyperlactatemia; (2) Survival benefit of the timely lactate measurement was proportional mediated through shortening the time to IVF; (3) Delayed initial lactate measurement showed a positive association with in-hospital mortality.

This is the first investigation to proof the benefit of timely lactate measurement in all patients with unstable hemodynamics (hypotension and hyperlactatemia) rather than just for septic. In our study, despite patients who had initial lactate measurements completed within $1 \mathrm{~h}$ had higher SOFA scores, higher initial lactate level and receive more mechanical ventilation and vasopressors, the in-hospital mortality was significantly lower among patients who had initial lactate measurements completed within $1 \mathrm{~h}$ after adjustment for confounding. This parallels the findings of previous limited researches, specifically for septic patients. A retrospective study conducted by $\mathrm{HC}$ et al. [21] declared that early lactate measurement (within $1 \mathrm{~h}$ after ICU admission) was associated with lower odds of 28-day mortality among septic patients with elevated serum lactate level. Similarly in Han et al.'s study [22], septic patients with delayed lactate measurements (lactate samples drawn more than $3 \mathrm{~h}$ after meeting severe sepsis criteria) demonstrated the highest in-hospital mortality than did patients who had lactate samples drawn within $3 \mathrm{~h}$. On the whole, our results accentuated an essential role of timely lactate measurement for all patients with unstable hemodynamics admitted to ICU.

Interestingly, the definition of "delay" was depend on the length of exposure to severe sepsis in Han's study, while the actual onset time of severe sepsis is unknown truthfully, which might occurred outside the ICU, moreover, the etiologies for patients with unstable hemodynamics were not always explicit [23, 24]. Although it's possible that patients would have received timely resuscitation regardless of the etiologies and whether the lactate level was measured or not, identifying patients could delay the lactate measurement and interventions. Thus, the "timely" in present study was beginning with the onset of ICU admission to led clinicians consider lactate draw earlier for all patients with suspected unstable hemodynamics. Additionally, Han et al. [22] detected a significant relationship between delay in initial lactate measurement and in-hospital death only in patients with an initial lactate value $>2.0$ $\mathrm{mmol} / \mathrm{L}$, raising the question that the initial lactate level or other clinical parameters associated with the severity of diseases might cause interaction effects between timely lactate measurement and mortality. However, no significant interactions were detected for initial lactate level, SOFA score and minimal MAP in both cohorts. Actually, there was no highly recognized factors that can represent the disease severity, and 
the mechanism underlying the interaction between these factors and timely lactate measurement is little known. More research is required to develop a deeper understanding of the interaction effects above.

What's more attractive is to investigate which factors were contribute to the benefit effects of timely lactate measurement in terms of in-hospital mortality. Therapeutic interventions have been shown to mediate this benefit effect in previous studies, including fluid resuscitation, administration of vasoactive agents, both of which were the important components of resuscitation in circulatory shock [25].

According to a randomized controlled trial by Jasen et al. [26], patients with lactate levels $>3.0 \mathrm{mmol} / \mathrm{L}$ in lactate group (with the objective of decreasing their lactate levels by $20 \%$ or more per $2 \mathrm{~h}$ in the initial $8 \mathrm{~h}$ of their ICU stays) received significantly more fluids and more vasodilator therapy during $0-8 \mathrm{~h}$ and had a lower hospital mortality compared to the control group. Besides, the time to initial therapeutic interventions were equally important. $\mathrm{HC}$ et al. [21] demonstrated that early lactate measurement (within $1 \mathrm{~h}$ after ICU admission) was associated with early antibiotic therapy and vasopressors administration in septic patients with lactate levels $>2.0 \mathrm{mmol} / \mathrm{L}$, and further confirmed that the time to initial vasopressors was proportional mediated the survival benefit effect of early lactate measurement. On the contrary, in our study, although patients in Lac-by1 group had a shorter time to IVF and vasopressors in both cohorts, we only found a significant mediation effect of time to IVF in MIMIC using CMA.

Adequate and timely fluid therapy is an essential part of resuscitation of circulatory shock even in cardiogenic shock. A Retrospective cohort study by Kuttab et al. [27] found that septic patients who were failed to achieving a $30 \mathrm{~mL} / \mathrm{kg}$ crystalloid bolus within 3 hours of sepsis onset was associated with increased odds of in-hospital mortality, irrespective of patients who were elderly, end-stage renal disease, heart failure or documented volume "overload". Still in Han et al.'s study [22], patients with lactate levels > $2.0 \mathrm{mmol} / \mathrm{L}$ in draw lactate group had a shorter time to IVF and a lower mortality compared with patients in delayed lactates group. Even though we detect no significant mediation effect of time to IVF in elCU, we should not underestimate the value of timely IVF in the management of shock, since our study is a retrospectively study performed on electronic health record data and require further investigate. Studies undertaken so far provide conflicting evidence concerning the impact of time to initial vasopressor on mortality in circulatory shock [28-30], the effectiveness of vasopressor depends on the type and severity of shock, and most patients would have vasopressors administrated prior to ICU admission in two cohorts. These might account for the insignificant mediation effect of time to initial vasopressors administration.

The strength of study was the use of MIMIC-III and elCU databases which contain comprehensive and high-quality data of well-defined and characterized ICU patients in 147 different hospitals from the USA. We also used model of PSM and IPTW to minimize confounding factors and robust our results. It is difficult to elucidate clearly on causality in a retrospective analysis, we apply the CMA to cover this shortage. The present research is also limited by several factors as follows: First, the diagnosis of circulatory shock is based on clinical, hemodynamic and biochemical markers, which summarized into three parts: systemic hypotension, clinical signs of tissue hypoperfusion and hyperlactatemia [25], it's impossible to assess the clinical signs of tissue hypoperfusion in our study, hence we only use 
hypotension and hyperlactatemia to represent the patients with circulatory shock; Second, our study ranging from 2001 till 2015, the versions of the bundles might have changed during the period, and the results may not be adapted to current practice, however, our results were adjusted for the admission period, in MIMIC, since we couldn't get the exact year of patients' admission, we divided patients into two groups in terms of admission year (before 2008 and 2008-2012). Third, lactate guiding resuscitation are intricacy in clinical ,more than just fluid and vasoactive agents. The etiologies of shock, the severity of shock and unmeasured confounding factors such the reaction and the decision of the clinicians on duty are all involved in the management of shock and need to be explored in future. Finally, lactate is an imperfect marker of anaerobic metabolism [31], and lactate cannot be used to guide resuscitation alone, tissue hypoxia should be assessed in a combined analysis including $\mathrm{ScvO}_{2}$ or indices derived from the veno-arterial carbon dioxide pressure gradient.

\section{Conclusion}

In our study, we found that patients with hypotension and hyperlactatemia in Lac-by1 group demonstrated a lower risk-adjusted in-hospital mortality, and this survival benefit was proportional mediated through shortening the time to IVF. Timely lactate measurement may hence be useful in all patients with circulatory shock or unstable hemodynamics.

\section{Abbreviations}

ICU: intensive care unit; MIMIC: the Medical Information Mart for Intensive Care;elCU: the elCU Collaborative Research Database; US: the United States; SQL: structured query language; IVF: intravenous fluid; IQR: interquartile range; PSM: Propensity score matching; IPTW: inverse probability of treatment weighing; CMA: causal mediation analysis; MAP: mean arterial pressure; OR: odds ratio; SOFA: Sequential Organ Failure Assessment; ACME: average causal mediation effect

\section{Declarations}

\section{Acknowledgments}

None

\section{Funding}

This study was supported by the Natural Science Foundation of Jiangsu Province (Grants No BK2019044200).

\section{Availability of data and material}


The datasets presented in the current study are available in the MIMIC III database (https://physionet.org/works/MIMICIIIClinicalDatabase/files/) and the elCU database (https://eicucrd.mit.edu/).

\section{Authors' contributions}

$\mathrm{HC}, \mathrm{XB}$ and $\mathrm{YX}$ contributed equally to this work. JJ conceptualized the research aims, planned the analyses, and guided the literature review. HC extracted the data from the MIMIC-III database. XB and YX participated in processing the data and performing the statistical analysis. $\mathrm{HC}$ wrote the first draft of the paper, and the other authors provided comments and approved the final manuscript.

\section{Ethic approval and consent to participate}

The study was an analysis of two third-party publicly available database with pre-existing institutional review board (IRB) approval.

\section{Consent for publication}

Not applicable.

\section{Competing interests}

The authors declare that they have no competing interests.

\section{References}

1. Cecconi M, De Backer D, Antonelli M, Beale R, Bakker J, Hofer C, Jaeschke R, Mebazaa A, Pinsky MR, Teboul JL, et al. Consensus on circulatory shock and hemodynamic monitoring. Task force of the European Society of Intensive Care Medicine. Intensive care medicine. 2014;40(12):1795-815.

2. Rhodes A, Evans LE, Alhazzani W, Levy MM, Antonelli M, Ferrer R, Kumar A, Sevransky JE, Sprung CL, Nunnally ME, et al. Surviving Sepsis Campaign: International Guidelines for Management of Sepsis and Septic Shock: 2016. Intensive care medicine. 2017;43(3):304-77.

3. Casserly B, Phillips GS, Schorr C, Dellinger RP, Townsend SR, Osborn TM, Reinhart K, Selvakumar N, Levy MM. Lactate measurements in sepsis-induced tissue hypoperfusion: results from the Surviving Sepsis Campaign database. Critical care medicine. 2015;43(3):567-73.

4. Bloos F, Zhang Z, Boulain T. Lactate-guided resuscitation saves lives: yes. Intensive care medicine. 2016;42(3):466-9. 
5. Dettmer M, Holthaus CV, Fuller BM. The impact of serial lactate monitoring on emergency department resuscitation interventions and clinical outcomes in severe sepsis and septic shock: an observational cohort study. Shock (Augusta Ga). 2015;43(1):55-61.

6. Kiyatkin ME, Bakker J. Lactate and microcirculation as suitable targets for hemodynamic optimization in resuscitation of circulatory shock. Curr Opin Crit Care. 2017;23(4):348-54.

7. Gu WJ, Zhang Z, Bakker J. Early lactate clearance-guided therapy in patients with sepsis: a metaanalysis with trial sequential analysis of randomized controlled trials. Intensive care medicine. 2015;41(10):1862-3.

8. Liu VX, Morehouse JW, Marelich GP, Soule J, Russell T, Skeath M, Adams C, Escobar GJ, Whippy A. Multicenter Implementation of a Treatment Bundle for Patients with Sepsis and Intermediate Lactate Values. Am J Respir Crit Care Med. 2016;193(11):1264-70.

9. Pruinelli L, Westra BL, Yadav P, Hoff A, Steinbach M, Kumar V, Delaney CW, Simon G. Delay Within the 3-Hour Surviving Sepsis Campaign Guideline on Mortality for Patients With Severe Sepsis and Septic Shock. Critical care medicine. 2018;46(4):500-5.

10. Levy MM, Evans LE, Rhodes A. The Surviving Sepsis Campaign Bundle: 2018 update. Intensive care medicine. 2018;44(6):925-8.

11. Zhang Z, Chen $\mathrm{K}, \mathrm{Ni} \mathrm{H}$, Fan $\mathrm{H}$. Predictive value of lactate in unselected critically ill patients: an analysis using fractional polynomials. Journal of thoracic disease. 2014;6(7):995-1003.

12. Gale SC, Kocik JF, Creath R, Crystal JS, Dombrovskiy VY. A comparison of initial lactate and initial base deficit as predictors of mortality after severe blunt trauma. J Surg Res. 2016;205(2):446-55.

13. Haas SA, Lange T, Saugel B, Petzoldt M, Fuhrmann V, Metschke M, Kluge S. Severe hyperlactatemia, lactate clearance and mortality in unselected critically ill patients. Intensive care medicine. 2016;42(2):202-10.

14. Houwink AP, Rijkenberg S, Bosman RJ, van der Voort PH. The association between lactate, mean arterial pressure, central venous oxygen saturation and peripheral temperature and mortality in severe sepsis: a retrospective cohort analysis. Crit Care (London England). 2016;20:56.

15. van Donkelaar CE, Dijkland SA, van den Bergh WM, Bakker J, Dippel DW, Nijsten MW, van der Jagt M. Early Circulating Lactate and Glucose Levels After Aneurysmal Subarachnoid Hemorrhage Correlate With Poor Outcome and Delayed Cerebral Ischemia: A Two-Center Cohort Study. Critical care medicine. 2016;44(5):966-72.

16. Johnson AE, Pollard TJ, Shen L, Lehman LW, Feng M, Ghassemi M, Moody B, Szolovits P, Celi LA, Mark RG. MIMIC-III, a freely accessible critical care database. Scientific data. 2016;3:160035.

17. Pollard TJ, Johnson AEW, Raffa JD, Celi LA, Mark RG, Badawi O. The elCU Collaborative Research Database, a freely available multi-center database for critical care research. Scientific data. 2018;5:180178.

18. Zhang Z. Propensity score method: a non-parametric technique to reduce model dependence. Annals of translational medicine. 2017;5(1):7. 
19. Graffeo N, Latouche A, Le Tourneau C, Chevret S. ipcwswitch: An R package for inverse probability of censoring weighting with an application to switches in clinical trials. Comput Biol Med. 2019;111:103339.

20. Zhang Z, Zheng C, Kim C, Van Poucke S, Lin S, Lan P. Causal mediation analysis in the context of clinical research. Annals of translational medicine. 2016;4(21):425.

21. Chen H, Zhao C, Wei Y, Jin J. Early lactate measurement is associated with better outcomes in septic patients with an elevated serum lactate level. Crit Care (London England). 2019;23(1):351.

22. Han X, Edelson DP, Snyder A, Pettit N, Sokol S, Barc C, Howell MD, Churpek MM. Implications of Centers for Medicare \& Medicaid Services Severe Sepsis and Septic Shock Early Management Bundle and Initial Lactate Measurement on the Management of Sepsis. Chest. 2018;154(2):302-8.

23. Hiemstra B, Eck RJ, Keus F, van der Horst ICC. Clinical examination for diagnosing circulatory shock. Curr Opin Crit Care. 2017;23(4):293-301.

24. Bhattacharjee P, Edelson DP, Churpek MM. Identifying Patients With Sepsis on the Hospital Wards. Chest. 2017;151(4):898-907.

25. Vincent JL, De Backer D. Circulatory shock. N Engl J Med. 2013;369(18):1726-34.

26. Jansen TC, van Bommel J, Schoonderbeek FJ, Sleeswijk Visser SJ, van der Klooster JM, Lima AP, Willemsen SP, Bakker J. Early lactate-guided therapy in intensive care unit patients: a multicenter, open-label, randomized controlled trial. Am J Respir Crit Care Med. 2010;182(6):752-61.

27. Kuttab HI, Lykins JD, Hughes MD, Wroblewski K, Keast EP, Kukoyi O, Kopec JA, Hall S, Ward MA. Evaluation and Predictors of Fluid Resuscitation in Patients With Severe Sepsis and Septic Shock. Critical care medicine. 2019;47(11):1582-90.

28. Hollenberg SM. Vasoactive drugs in circulatory shock. Am J Respir Crit Care Med. 2011;183(7):84755.

29. Squara P, Hollenberg S, Payen D. Reconsidering Vasopressors for Cardiogenic Shock: Everything Should Be Made as Simple as Possible, but Not Simpler. Chest. 2019;156(2):392-401.

30. Tarvasmaki T, Lassus J, Varpula M, Sionis A, Sund R, Kober L, Spinar J, Parissis J, Banaszewski M, Silva Cardoso J, et al. Current real-life use of vasopressors and inotropes in cardiogenic shock adrenaline use is associated with excess organ injury and mortality. Crit Care (London England). 2016;20(1):208.

31. Suetrong B, Walley KR. Lactic Acidosis in Sepsis: It's Not All Anaerobic: Implications for Diagnosis and Management. Chest. 2016;149(1):252-61.

\section{Figures}


Multivariate Model

CBPS as Covariate

IPTW

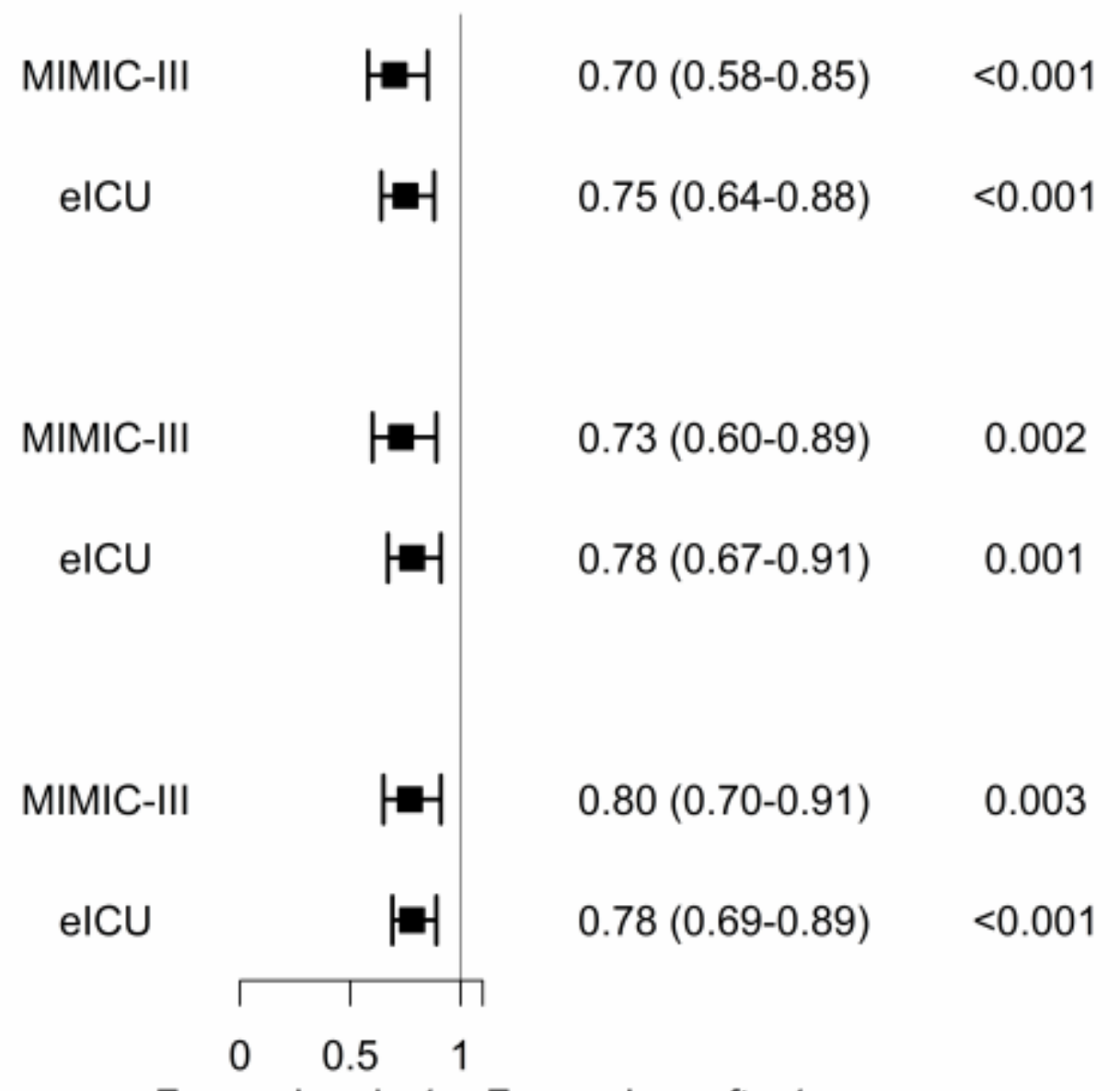

Favour Lac-by1 Favour Lac-after1

Figure 1

Association between timely lactate measurement and in-hospital mortality. The odds ratios and 95\% confidence intervals (error bars) in both cohorts were calculated dependent on method of covariate adjustment. CBPS: covariate balancing propensity score, IPTW: inverse probability of treatment weight. 


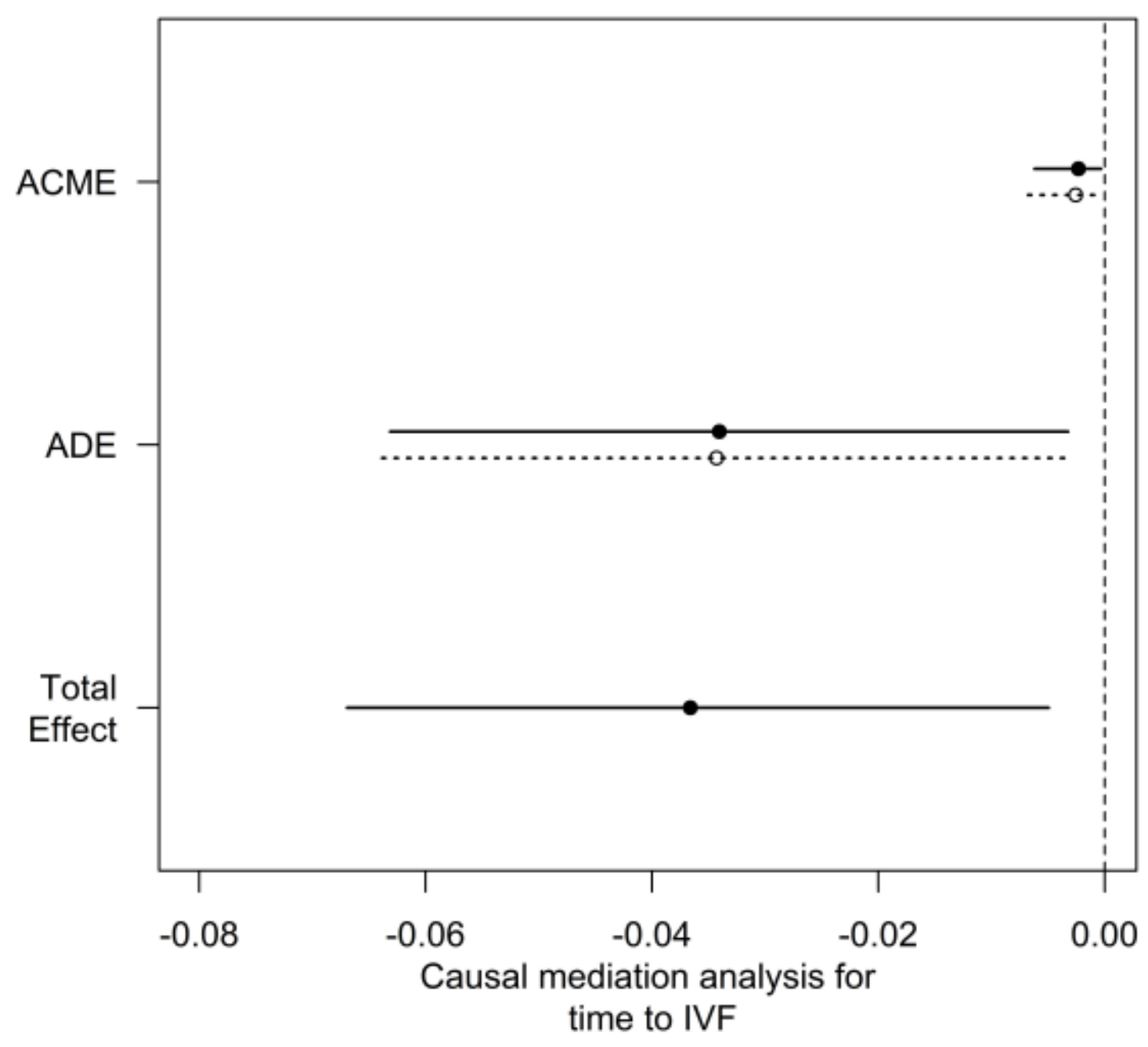

Figure 2

Causal mediation analysis for time to IVF. The solid line represents the Lac-by1, and the dashed line represents the Lac-after1. 
A

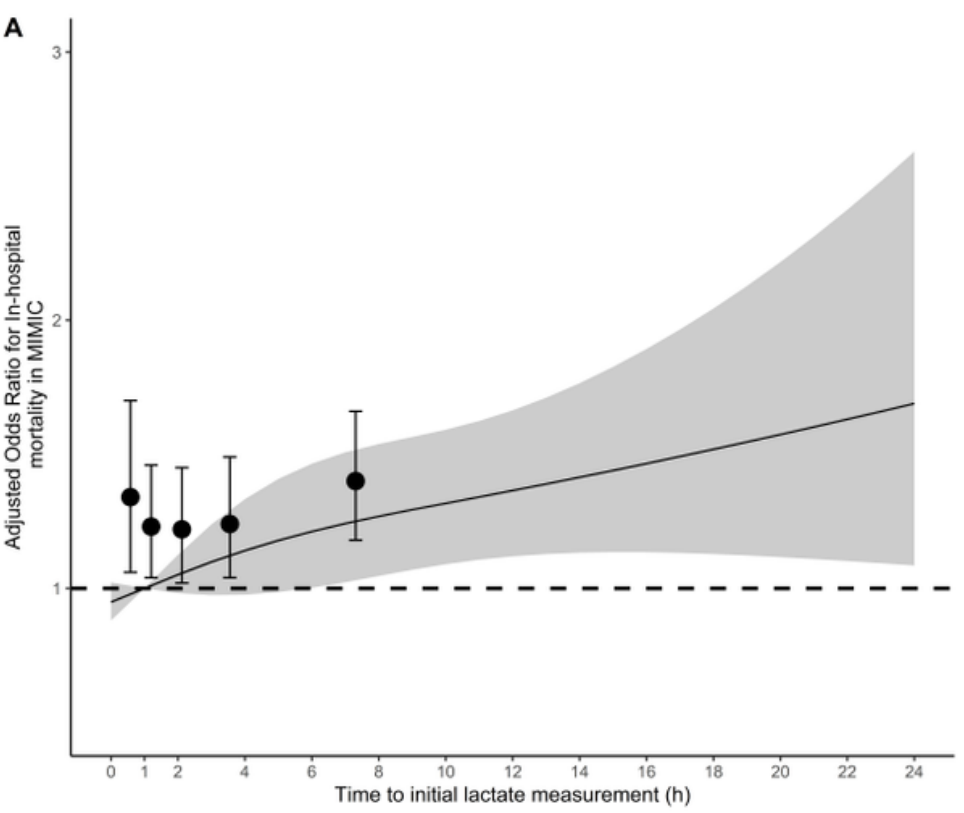

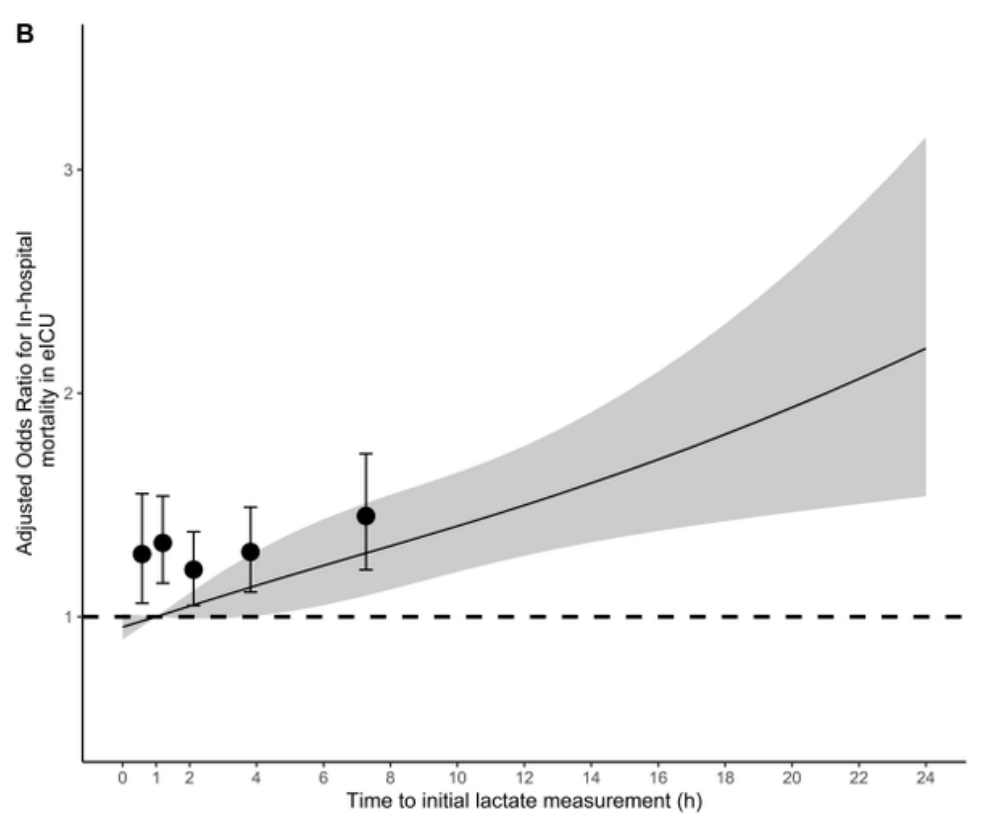

Figure 3

Relationship between delay in initial lactate measurement and in-hospital mortality. Figure 3 shows the increase in the adjusted odds of in-hospital mortality as a contribution of progressive percentiles of time to initial lactate measurement in two cohorts. The mean odds and $95 \%$ confidence intervals (error bars) for each percentile were calculated after multivariate adjustment. The gray zone represents the $95 \%$ confidence interval for in-hospital mortality risk when time to initial lactate measurement is considered as a continuous variable.

\section{Supplementary Files}

This is a list of supplementary files associated with this preprint. Click to download.

- Supplementary.docx 